KREATIF : Jurnal Ilmiah Prodi Manajemen Universitas Pamulang, Vol. 8, No.2, Desember 2020

\section{KREATIF \\ Jurnal IImiah}

@ Prodi Manajemen Fakultas Ekonomi Universitas Pamulang

ISSN : 2339 - 0689, E-ISSN : 2406-8616

J. KREATIF, Vol. 8 No.2, Desember 2020 (Halaman 92-101)

Tersedia Online di :http://openjournal.unpam.ac.id/index.php/kreatif

\title{
KINERJA PEGAWAI BERBASIS KEPEMIMPINAN DAN LINGKUNGAN KERJA PADA PT VICTORY CHINGLUH INDONESIA DIVISI QUALITY
}

\author{
Ading Sunarto \\ Program Studi Manajemen Fakultas Ekonomi Universitas Pamulang \\ email : dosen02153@unpam.ac.id
}

\begin{abstract}
ABSTRAK
Tujuan penelitian ini adalah untuk melihat seberapa besarnya pengaruh kepemimpinan dan lingkungan kerja terhadap kinerja pegawai PT. Victory Chingluh Indonesia Divisi Quality.

Pada penelitian ini konsep yang dipakai yaitu konsep deskriptif dengan menggunakan pendekatan asosiatif. Teknik sampel yang dipakai yaitu proporsional random sampling dengan jumlah sampel sejumlah 64 responden. Metode statististik untuk menganalisis yang dipakai yaitu uji validitas, uji reliabilitas, uji asumsi klasik, analisis regresi, analisis koefisien korelasi, analisis koefisien determinasi serta uji hipotesis.

Hasil dari penelitiannya yaitu kepemimpinan berpengaruh signifikan pada kinerja pegawai, Lingkungan kerja berpengaruh signifikan antara lingkungan kerja pada kinerja pegawai. Kepemimpinan dan lingkungan kerja secara bersama-sama berpengaruh signifikan pada kinerja pegawai.
\end{abstract}

Keywords : Kepemimpinan, Lingkungan Kerja, Kinerja Pegawai

\section{ABSTRACT}

The purpose of this study is to see how much influence the leadership and work environment have on the performance of employees of PT. Victory Chingluh Indonesia Quality Division.

In this study, the concept used is a descriptive concept using an associative approach. The sample technique used is proportional random sampling with a sample size of 64 respondents. Statistical methods used to analyze used are validity test, reliability test, classical assumption test, regression analysis, correlation coefficient analysis, determination coefficient analysis and hypothesis testing.

The results of his research are leadership has a significant effect on employee performance. The work environment has a significant effect on employee performance. Leadership and work environment together have a significant effect on employee performance.

Keywords: Leadership, Work Environment, Employee Performance

\section{PENDAHULUAN}

\section{A. Latar Belakang Masalah}

Pegawai pada suatu organisasi perusahaan merupakan aset berharga dalam pencapaian tujuan suatu organisasi termasuk pada PT. Victory Chingluh Indonesia Divisi Quality, dimana bila pegawai dapat memperoleh kinerja yang baik, maka dapat menghasilkan kontribusi yang maksimal dalam menjalankan aktivitas kegiatan suatu perusahaan. Dengan hasil kerja yang baik maka setiap pegawai mampu mengatasi apapun beban organisasi 
KREATIF : Jurnal Ilmiah Prodi Manajemen Universitas Pamulang, Vol. 8, No.2, Desember 2020

dengan efektif serta efisien, oleh karena itu permasalahan yang terjadi pada organisasi/instansi dapat diselesaikan dengan baik. Kinerja pegawai juga dapat dilihat dari aspek kualitas kerja, kuantitas banyaknya kerja, pelaksanaan tugas, tanggung jawab dan inisiatif.

Kepemimpinan seorang leader dalam suatu perusahaan sangat penting karena pimpinan mempunyai fungsi yang strategis dan penting dalam mencapai tujuan sebuah perusahaan. Menurut Sutikno (2014:16) Kepemimpinan merupakan suatu proses dimana seorang leader bisa secara langsung mengarahkan \& memberikan pengaruh prilaku \& pekerjaan lainnya agar menuju pencapaian dalam keadaan tertentu.

Lingkungan kerja melihat pada suatu hal yang berada di sekitar lingkungan dan meliputi karyawan di sebuah perusahaan. Sunyoto (2015:43) berpendapat bahwa Lingkungan kerja ialah apapun yang terdapat diantara para pegawai dan yang bisa mempengaruhi individu dalam melaksanakan tugas pekerjaan yang diberikan contohnya kebersihan, pencahayaan, suara bising dan lain-lain. Sementara Siagian (2014:56) menyampaikan bahwa lingkungan kerja yaitu lingkungan dimana pekerja menjalankan pekerjaannya sehari-harinya.

Dengan perencanaan SDM yang terencana, hasil kerja yang telah ada bisa lebih dimaksimalkan. Hal ini bisa diwujudkan melewati adanya adaptasi, misalnya peningkatan kepemimpinan dan lingkungan kerja yang bagus. Jadi setiap pegawai bisa memperoleh hal yang berkaitan langsung dengan kepentingan perusahaan.

Kinerja merupakan sesuatu hal tentang tingkat perolehan pelaksanaan sesuatu program-program kegiatan ataupun aturan dalam mencapai sasaran, tujuan, visi serta misi perusahaan yang disampaikan lewat perencanaan strategis sebuah organisasi perusahaan. Menurut Abdullah (2014:3-4) Kinerja adalah sebuah prestasi kerja yang merupakan hasil penerapan plan kerja yang dibentuk oleh organisasi yang dijalankan oleh leader dan pekerja atau SDM yang ada di perusahaan itu baik pemerintah maupun perusahaan swasta (bisnis) untuk mencapai tujuan perusahaan.

Agar tergapai tujuannya Kinerjanya yang baik dapat dicapai dengan adanya sebuah kesadaran setiap leader dalam memberikan support kepada karyawan berupa keterlibatan leader dalam memberikan motivasi mengenai job yang dilakukan oleh setiap karyawan.

Kegiatan PT. Victory Chingluh Indonesia Divisi Quality dibuat menurut konsep ramah terhadap lingkungan kerja yang efisien, dan karyawan yang terlatih dan terdidik agar dapat menghasilkan sepatu dengan merek Nike yang berkualitas high untuk para konsumen. Kesuksesan dalam menggapai tujuan organisasi hanya akan dicapai jika pegawai yang ada bekerja dengan kinerja yang baik atau optimal. Pada pengamatan peneliti, kepemimpinan dan lingkungan kerja PT. Victory Chingluh Indonesia Divisi Quality, masih perlu lebih ditingkatkan hal ini dapat dilihat dari permasalahan yaitu : tidak semua karyawan dalam menjalankan tugas tepat waktu, masih ada pekerjaan karyawan yang masih belum diselesaikan dalam bekerja, melakukan kerja hanya sebatas rutinitas saja. Jadi dilihat dari permasalahan itu kinerja pekerja sangat lah mengalami penurunan, oleh karenanya mengakibatkan kinerja dalam perusahaan tidak maksimal.

Base on data yang diperoleh dari PT. Victory Chingluh Indonesia Divisi Quality, kepemimpinan yang belum maksimal dan lingkungan kerja yang kurang kondusif mengakibatkan kinerja karyawan menurun, hal itu bisa dilihat dari data hasil produksi mulai tahun 2017-2019 sebagai berikut:

\begin{tabular}{|l|l|l|} 
Bulan & Target Per Tahun $\quad$ Output Per Tahun \\
\cline { 2 - 2 }
\end{tabular}


KREATIF : Jurnal Ilmiah Prodi Manajemen Universitas Pamulang, Vol. 8, No.2, Desember 2020

\begin{tabular}{|l|c|c|c|c|c|c|}
\hline \multirow{2}{*}{} & \multicolumn{3}{|c|}{ (Prs/Pasang) } & \multicolumn{3}{c|}{ (Prs/Pasang) } \\
\cline { 2 - 7 } & $\mathbf{2 0 1 7}$ & $\mathbf{2 0 1 8}$ & $\mathbf{2 0 1 9}$ & $\mathbf{2 0 1 7}$ & $\mathbf{2 0 1 8}$ & $\mathbf{2 0 1 9}$ \\
\hline Januari & 43,960 & 43,517 & 39,495 & 42,646 & 41,429 & 40,695 \\
\hline Februari & 39,108 & 37,720 & 33,130 & 36,711 & 37,205 & 28,953 \\
\hline Maret & 42,008 & 38,963 & 25,483 & 39,988 & 37,360 & 23,020 \\
\hline April & 44,935 & 58,917 & 35,241 & 43,846 & 40,814 & 32,582 \\
\hline Mei & 46,246 & 42,446 & 28,500 & 46,473 & 39,405 & 26,369 \\
\hline Juni & 18,670 & 28,422 & 20,706 & 18,956 & 24,175 & 18,950 \\
\hline Juli & 40,633 & 43,937 & 31,113 & 37,202 & 42,541 & 30,510 \\
\hline Agustus & 39,737 & 42,383 & 29,263 & 36,410 & 40,469 & 30,458 \\
\hline September & 28,788 & 39,223 & 29,313 & 26,707 & 34,893 & 32,281 \\
\hline Oktober & 32,582 & 41,760 & 30,109 & 29,329 & 42,142 & 32,767 \\
\hline November & 34,259 & 37,196 & 32,949 & 32,147 & 39,881 & 33,958 \\
\hline Desember & 39,384 & 27,554 & 25,193 & 36,695 & 29,576 & 21,855 \\
\hline Jumlah & 450,309 & 482,038 & 360,495 & 427,110 & 449,890 & 352,398 \\
\hline
\end{tabular}

Gambar 1. Data Produksi Sepatu Nike PT. Victory Chingluh Indonesia Divisi

Quality 2017-2019

Berdasarkan tabel di atas, sepatu yang di produksi mengalami punurunan dan masih belum berhasil diraih sesuai dengan target yang telah ditentukan organisasi. Tahun 2017 mencapai produksi sebanyak 427,110. Tahun 2018 mencapai produksi sebanyak 449,890 dan pada tahun 2019 mencapai produksi sebanyak 352,398. Penurunan produksi terendah terlihat pada tahun 2019 yaitu 352,398 pasang sepatu. Maka dilihat dari data produksi karyawan PT. Victory Chingluh Indonesia Divisi Quality mengalami naik turun pada tahun 2017 sampai dengan tahun 2019. Menurut Suryono Ekotama (2015:224) cara mengantisipasi penurunan kinerja adalah salah satunya dengan melakukan evaluasi kerja berkala, minimal sebulan sekali dengan demikian kita akan tahu apakah kinerja karyawan meningkat, stabil, atau mengalami penurunan.

Dalam aspek pencapain kinerja harus lebih dioptimalkan kembali mengingat masih ada target dari perusahaan yang belum diselesaikan dengan baik, utamanya menyangkut aspekaspek yang berhubungan dengan keteladanan, kewibawaan, pendelegasian tugas, pengambilan keputusan dan motivasi, serta lingkungan kerja yang kondusif untuk pegawai.

Berdasarkan penjelasan tersebut, oleh karenanya penulis berniat untuk membuat penelitian berjudul "Kinerja karyawan berbasis kepemimpinan dan lingkungan kerja pada PT. Victory Chingluh Indonesia Divisi Quality".

\section{B. Rumusan Masalah}

Berdasarkan paparan sebelumnya, maka penulis rumuskan masalahnya antara lain:

1) Bagaimanakah Pengaruh Kepemimpinan Pada Kinerja Karyawan PT. Victory Chingluh Indonesia Divisi Quality?

2) Bagaimanakah Pengaruh Lingkungan Kerja Pada Kinerja Pegawai PT. Victory Chingluh Indonesia Divisi Quality?

3) Bagaimanakah Pengaruh Kepemimpinan serta Lingkungan Kerja terhadap Kinerja Pegawai PT. Victory Chingluh Indonesia Divisi Quality secara bersamaan?

C. Tujuan Penelitian 
KREATIF : Jurnal Ilmiah Prodi Manajemen Universitas Pamulang, Vol. 8, No.2, Desember 2020

Penelitian ini memiliki maksud dan tujuan antara lain:

1) Melihat pengaruh Kepemimpinan pada kinerja pegawai PT. Victory Chingluh Indonesia Divisi Quality.

2) Melihat pengaruh Lingkungan Kerja pada kinerja pegawai PT. Victory Chingluh Indonesia Divisi Quality.

3) Melihat pengaruh Kepemimpinan serta Lingkungan Kerja terhadap Kinerja Pegawai PT. Victory Chingluh Indonesia Divisi Quality secara bersamaan.

\section{METODE PENELITIAN}

\section{A. Populasi dan Sampel}

Menurut Wirawan (2015:735) Populasi merupakan gabungan individual orang atau objek yang menjadi fokus penelitian saintifik. Menurut Sugiyono (2012:116), Sampel merupakan bagian dari total serta ciri khas yang dipunyai oleh populasi tersebut. Objek dalam penelitian ini yaitu pegawai pada PT. Victory Chingluh Indonesia Divisi Quality dengan total sampel sejumlah 64 pekerja. Peneliti mengambil teknik sampel jenuh sebab semua populasi yang ada dijadikan sampel.

\section{B. Jenis dan Sumber Data}

Menurut Supangat (2008:2) data ialah bentuk keseluruhan dari datum, yang bisa dijelaskan sebagai inforrmasi yang didapatkan yang bentuknya bisa berupa angka, katakata, ataupun berupa ucapan dan tulisan lainnya. Macam data yang dipakai yaitu kuantitatif dengan sumber data primer yaitu dengan cara membagikan kuesioner yang seterusnya dilakukan tabulasi serta analisis kelayakan dengan menggunakan penghitungan statistik menggunakan SPSS serta data sekunder yang asalnya dari macam-macam literasi di bidang keilmuan.

\section{Penilaian Instrumen Data}

Pengujian alat atau instrumen yang digunakan yaitu dengan uji validitas serta reliabilitas. Menurut Ghozali (2011:142), uji validitas dipakai untuk mengetahui syah/valid atau tidaknya suatu kuesioner. Sebuah kuesioner dianggap valid jika pertanyaan atau pernyataan pada kuesioner dapat menjelaskan sesuatu yang akan diukur oleh kuesioner itu sendiri, validitas menjelaskan sejauh mana alat pengukur yang dipakai untuk mengukur apa yang diukur. Dari uji validitas \& reliabilitas dikatakan valid dan reliabel, hal itu dapat dibuktikan oleh nilai $r$ hitung yang lebih besar dari $r$ tabel, demikian pula instrumen yang digunakan sudah tepat serta layak untuk dilanjutkan ke pengujian selanjutnya.

\section{Uji Kelayakan Data atau uji Asumsi Klasik}

Uji normalitas yang dipakai yaitu Kolmogorov Smirnof diperoleh signifikansi lebih besar dari 0,50 dengan demikian dinyatakan normal.

Pengujian Multikolinieritas diperoleh nilai toleransi $<1$ dan VIF $<10$ sehingga disimpulkan tidak ada gangguan multikolinieritas.

Pengujian autokorelasi didapatkan nilai Durbin Watson berada pada interval 1,550 - 2,460, dengan begitu model regresi ini tidak terdapat autokorelasi.

Pengujian Heteroskesdastisitas dengan uji Glejser diperoleh nilai signifikansi > 0,05 jadi dikatakan tidak terjadi gangguan heteroskesdastisitas. 
KREATIF : Jurnal Ilmiah Prodi Manajemen Universitas Pamulang, Vol. 8, No.2, Desember 2020

\section{HASIL DAN PEMBAHASAN}

\section{A. Analisis Deskriptif}

Kriteria dari objek yang diteliti base on respons responden di butir pertanyaan terkait variabel kepemimpinan $\left(\mathrm{X}_{1}\right)$ secara keseluruhan didapatkan rata-rata skor sebesar 3,76, lingkungan kerja $\left(\mathrm{X}_{2}\right)$ diperoleh rata-rata skor senilai 3,82 dan kinerja karyawan (Y) didapatkan rata-rata skor sebesar 3,88.

\section{B. Analisis Verifikatif}

Analisis ini bertujuan untuk melihat berapa besar pengaruh antar variabel dan untuk menganalisis tingkat signifikansi dari pengaruh tersebut. Pada analisis verifikatif ini dilakukan uji terhadap pengaruh dua variabel independen terhadap variabel dependen baik secara sebagian ataupun secara bersama-sama.

\section{a. Analisis Regresi Linier Berganda.}

Suatu model regresi dipakai untuk melihat peramalan suatu model yang sesuai ialah model dengan kesalahan peramalan yang sekecil mungkin menurut Santoso (2009:342). Pengujian regresi berganda ini bertujuan guna melihat seberapa besar pengaruh antara variabel $\mathrm{X}_{1}$ dan $\mathrm{X}_{2}$ terhadap variabel $\mathrm{Y}$. Di dalam penelitian ini yaitu kepemimpinan $\left(\mathrm{X}_{1}\right)$ dan lingkungan kerja $\left(\mathrm{X}_{2}\right)$ terhadap kinerja pegawai $(\mathrm{Y})$. Di bawah ini hasil olahan data regresinya:

Tabel 1. Hasil Olahan Regresi Berganda Variabel Kepemimpinan $\left(X_{1}\right)$ dan Lingkunga Kerja $\left(\mathbf{X}_{2}\right)$ Terhadap Kinerja Pegawai $(\mathbf{Y})$

\begin{tabular}{|c|c|c|c|c|c|c|}
\hline \multicolumn{7}{|c|}{ Coefficients $^{\mathbf{a}}$} \\
\hline \multirow{2}{*}{\multicolumn{2}{|c|}{ Model }} & \multicolumn{2}{|c|}{$\begin{array}{l}\text { Unstandardised } \\
\text { Coefficients }\end{array}$} & \multirow{2}{*}{$\begin{array}{c}\text { Standardized } \\
\text { Coefficients } \\
\text { Beta }\end{array}$} & \multirow[b]{2}{*}{$\mathrm{T}$} & \multirow[b]{2}{*}{ Sig. } \\
\hline & & B & $\begin{array}{l}\text { Std. } \\
\text { Error }\end{array}$ & & & \\
\hline 1 & (Constants) & 7.374 & 3.492 & & 2.112 & .039 \\
\hline & Kpemimpinan (X1) & .230 & .080 & .249 & 2.856 & .006 \\
\hline & $\begin{array}{l}\text { Lingkungan Kerja } \\
\text { (X2) }\end{array}$ & .628 & .083 & .660 & 7.577 & .000 \\
\hline
\end{tabular}

Base on hasil hitungan regresi pada tabel di atas, dapat dihasilkan persamaan regresi $\mathrm{Y}=7,374+0,230 \mathrm{X}_{1}+0,628 \mathrm{X}_{2}$. Berdasarkan persamaan tersebut diatas dapat dibuat kesimpulan :

1) Hasil dari konstanta senilai 7,374 dimaksudkan bahwa apabila variabel kepemimpinan $\left(\mathrm{X}_{1}\right)$ dan lingkungan kerja $\left(\mathrm{X}_{2}\right)$ tidak ada maka sudah ada nilai kinerja pegawai (Y) senilai 7,374 point.

2) Hasil 0,230 dimaksudkan jika konstanta tetap serta nol perubahan pada variabel lingkungan kerja $\left(\mathrm{X}_{2}\right)$, jadi setiap perubahan satu unit pada variabel kepemimpinan $\left(\mathrm{X}_{1}\right)$ akan menyebabkan terjadinya perubahan pada kinerja pegawai (Y) senilai 0,230 point.

3) Hasil 0,628 dimaksudkan jika konstanta tetap dan nol perubahan pada variabel kepemimpinan $\left(\mathrm{X}_{1}\right)$, jadi setiap perubahan satu unit dari variabel lingkungan kerja $\left(\mathrm{X}_{2}\right)$ akan menyebabkan terjadinya perubahan pada kinerja pegawai $(\mathrm{Y})$ sebanyak 0,628 point. 
KREATIF : Jurnal Ilmiah Prodi Manajemen Universitas Pamulang, Vol. 8, No.2, Desember 2020

\section{b. Analisis Koefisien Determinasi ( $R$ Square).}

Analisis koefisien determinasi bertujuan memperlihatkan prosentase kontribusi pengaruh antara variabel independen terhadap variabel dependen baik dengan sebagian ataupun secara bersama-sama. Di bawah ini hasil perhitungan koefisien determinasi:

Tabel 2. Hasil Analisis Koefisien Determinasi Secara Sebagian Antara Kepemimpinan $\left(\mathrm{X}_{1}\right)$ Terhadap Kinerja Pegawai $(Y)$

\begin{tabular}{|c|c|c|c|c|}
\hline \multicolumn{5}{|c|}{ Model Summary } \\
\hline Model & $\mathrm{R}$ & R Square & $\begin{array}{c}\text { Adjusted R } \\
\text { Square }\end{array}$ & $\begin{array}{l}\text { Std. Error of } \\
\text { the Estimate }\end{array}$ \\
\hline 1 & $.620^{\mathrm{a}}$ & .385 & .375 & 3.488 \\
\hline
\end{tabular}

Base on hasil pengujian pada tabel, diketahui nilai $R$-Square atau determinasi senilai 0,385 , hal ini menjelaskan bahwa kontribusi pengaruh antara kepemimpinan terhadap kinerja pegawai sebanyak 38,5\%, sementara sisanya senilai $61,5 \%$ dipengaruhi oleh faktor lainnya yang tidak diteliti.

Tabel 3. Hasil Analisis Koefisien Determinasi Secara Sebagian Antara Lingkungan Kerja $\left(\mathbf{X}_{2}\right)$ Terhadap Kinerja Pegawai (Y)

\begin{tabular}{|l|c|r|r|r|}
\hline \multicolumn{5}{|c|}{ Model Summary } \\
\hline Model & $\mathrm{R}$ & R Square & $\begin{array}{c}\text { Adjusted R } \\
\text { Square }\end{array}$ & $\begin{array}{c}\text { Std. Error of } \\
\text { the Estimate }\end{array}$ \\
\hline 1 & $.800^{\mathrm{a}}$ & .641 & .635 & 2.666 \\
\hline a. Predictors: (Constant),Lingkungan Kerja(X2) \\
\hline
\end{tabular}

Melalui uji tersebut, didapatkan nilai $R$-Square atau determinasi sebanyak 0,641, hal ini menyatakan bahwa kontribusi pengaruh antara kepemimpinan terhadap kinerja pegawai sebanyak $64,1 \%$, sementara sisanya sebesar 35,9\% dipengaruhi oleh faktor lain yang tidak diteliti.

Tabel 4. Hasil Analisis Koefisien Determinasi Secara Bersama-sama Antara Kepemimpinan $\left(X_{1}\right)$ dan Lingkungan Kerja (X2) Terhadap Kinerja Karyawan (Y)

\begin{tabular}{|l|r|r|r|c|}
\hline \multicolumn{6}{|c|}{ Model Summary } \\
\hline $\begin{array}{l}\text { Mode } \\
1\end{array}$ & $\mathrm{R}$ & R Square & $\begin{array}{c}\text { Adjusted R } \\
\text { Square }\end{array}$ & $\begin{array}{l}\text { Std. Error of the } \\
\text { Estimate }\end{array}$ \\
\hline 1 & $.826^{\mathrm{a}}$ & .683 & .673 & 2.524 \\
\hline
\end{tabular}

a.Predictors:(Constant), Lingkungan Kerja (X2), Kepemimpinan (X1)

Melalui tabel tersebut, didapatkan nilai $R$-Square atau determinasi senilai 0,683, hal ini mengindikasikan bahwa kontribusi pengaruh kepemimpinan serta lingkungan kerja secara bersamaan terhadap kinerja pegawai sebanyak 68,3\%, sementara senilai $31,7 \%$ sisanya dipengaruhi faktor lain yang tidak diteliti oleh penulis.

\section{c. Uji Hipotesis}

1) Uji Hipotesis Sebagian (Uji t). 
KREATIF : Jurnal Ilmiah Prodi Manajemen Universitas Pamulang, Vol. 8, No.2, Desember 2020

Dalam uji hipotesis kepemimpinan $\left(\mathrm{X}_{1}\right)$ dan lingkungan kerja $\left(\mathrm{X}_{2}\right)$ terhadap kinerja pegawai (Y) dihitung menggunakan uji statistik t (uji secara sebagian).

(a) Pengaruh Kepemimpinan $\left(\mathrm{X}_{1}\right)$ Terhadap Kinerja Pegawai $(\mathrm{Y})$

Untuk olahan data melalui aplikasi SPSS versi 26, dengan hasil yaitu:

Tabel 5. Hasil Uji t Kepemimpinan $\left(\mathbf{X}_{1}\right)$

\begin{tabular}{|c|c|c|c|c|c|c|}
\hline \multicolumn{7}{|c|}{ Coefficients $^{\mathbf{a}}$} \\
\hline \multirow{2}{*}{\multicolumn{2}{|c|}{ Model }} & \multicolumn{2}{|c|}{$\begin{array}{c}\text { Unstandardized } \\
\text { Coefficients }\end{array}$} & \multirow{2}{*}{$\begin{array}{c}\text { Standardize } \\
\text { d } \\
\text { Coefficient } \\
\text { s } \\
\\
\text { Beta } \\
\end{array}$} & \multirow[b]{2}{*}{$\mathrm{t}$} & \multirow[b]{2}{*}{ Sig. } \\
\hline & & $\mathrm{B}$ & $\begin{array}{l}\text { Std. } \\
\text { Error }\end{array}$ & & & \\
\hline 1 & (Constant) & $\begin{array}{r}20.70 \\
5 \\
\end{array}$ & 4.169 & & 4.967 & .000 \\
\hline & $\begin{array}{l}\text { Kepemimpi } \\
\operatorname{nan}(\mathrm{X} 1)\end{array}$ & .572 & .092 & .620 & 6.226 & .000 \\
\hline
\end{tabular}

Menurut hasil pengujian di atas didapatkan nilai $t_{\text {hitung }}>t_{\text {tabel }}$ atau $(6,226>1,999)$ Hal itu diperkuatkan dengan nilai $\rho$ value $<$ Sig.0,05 atau $(0,000<0,05)$. Oleh karena itu maka $\mathrm{H}_{0}$ tidak diterima lalu $\mathrm{H}_{1}$ diterima, hal ini membuktikan bahwa ada pengaruh yang signifikan secara sebagian antara kepemimpinan terhadap kinerja pegawai.

(b) Pengaruh Lingkunga Kerja $\left(\mathrm{X}_{2}\right)$ Terhadap Kinerja Pegawai (Y) Tabel 6. Hasil Uji t Lingkungan Kerja $\left(\mathbf{X}_{2}\right)$

\begin{tabular}{|c|c|c|c|c|c|c|}
\hline \multicolumn{7}{|c|}{ Coefficients $^{\mathrm{a}}$} \\
\hline \multirow{2}{*}{\multicolumn{2}{|c|}{ Model }} & \multicolumn{2}{|c|}{$\begin{array}{l}\text { Unstandardized } \\
\text { Coefficients }\end{array}$} & \multirow{2}{*}{$\begin{array}{c}\begin{array}{c}\text { Standardize } \\
\text { d } \\
\text { Coefficient } \\
\text { s }\end{array} \\
\text { Beta }\end{array}$} & \multirow[b]{2}{*}{$\mathrm{t}$} & \multirow[b]{2}{*}{ Sig. } \\
\hline & & $\mathrm{B}$ & $\begin{array}{l}\text { Std. } \\
\text { Error }\end{array}$ & & & \\
\hline 1 & (Constant) & $\begin{array}{r}11.63 \\
7\end{array}$ & 3.334 & & 3.490 & .001 \\
\hline & $\begin{array}{l}\text { Lingkungan } \\
\text { Kerja (X2) }\end{array}$ & .761 & .072 & .800 & $\begin{array}{r}10.51 \\
3\end{array}$ & .000 \\
\hline
\end{tabular}

Menurut hasil pengujian di tabel di atas didapatkan nilai $t_{\text {hitung }}$ lebih besar dari tabel atau $(10,513>1,999)$, ini dikuatkan dengan $\rho$ value $<$ Sig.0,05 atau $(0,000<0,05)$. Oleh karena itu $\mathrm{H}_{0}$ ditolak lalu $\mathrm{H}_{2}$ diterima, menjelaskan bahwa ada pengaruh yang signifikan secara sebagian antara lingkungan kerja terhadap kinerja pegawai.

\section{2) Uji Hipotesis Bersamaan (Uji F).}


KREATIF : Jurnal Ilmiah Prodi Manajemen Universitas Pamulang, Vol. 8, No.2, Desember 2020

Pengujian pengaruh kepemimpinan dan lingkungan Kerja secara bersamaan terhadap kinerja pegawai melalui uji statistik $\mathrm{F}$ (uji secara bersamaan/simultan) dengan signifikansi $5 \%$.

Tabel 7. Hasil Hipotesis (Uji F) Simultan

\begin{tabular}{|c|c|c|c|c|c|c|}
\hline \multicolumn{7}{|c|}{ ANOVA $^{\mathrm{a}}$} \\
\hline \multicolumn{2}{|c|}{ Model } & $\begin{array}{c}\text { Sum } \\
\text { ofSquares }\end{array}$ & df & $\begin{array}{c}\text { MeanSquar } \\
\mathrm{e}\end{array}$ & $\mathrm{F}$ & Sig. \\
\hline 1 & Regression & 837.364 & 2 & 418.682 & $\begin{array}{r}65.71 \\
9\end{array}$ & $.000^{\mathrm{b}}$ \\
\hline & Residual & 388.620 & 61 & 6.371 & & \\
\hline & Total & 1225.984 & 63 & & & \\
\hline
\end{tabular}

Menurut hasil uji di tabel di atas didapatkan nilai $F_{\text {hitung }}$ lebih besar dari $\mathrm{F}_{\text {tabel }}$ atau $(65,719>2,760)$, ini dikuatkan dengan $\rho$ value $<$ Sig.0,05 atau $(0,000<0,05)$. Oleh karena itu $\mathrm{H}_{0}$ tidak diterima lalu $\mathrm{H}_{3}$ diterima, hal ini membuktikan bahwa ada pengaruh yang signifikan secara bersama-sama antara kepemimpinan serta lingkungan kerja terhadap kinerja pegawai PT. Victory Chingluh Indonesia Divisi Quality.

\section{Pembahasan}

\section{Pengaruh Kepemimpinan $\left(X_{1}\right)$ Terhadap KinerjaPegawai (Y)}

Menurut uji statistik, didapatkan koefisien determinasi sebanyak 0,385 atau sejumlah $38,5 \%$ sementara sisanya $61,5 \%$ dipengaruhi oleh faktor lainnya. Uji hipotesis didapatkan $t$ hitung lebih besar dari t tabel atau $(6,226>1,999)$, dengan begitu $\mathrm{H}_{0}$ tidak diterima dan $\mathrm{H}_{1}$ diterima ini berarti bahwa ada pengaruh yang signifikan secara sebagian antara kepemimpinan dengan kinerja pegawai.

2. Pengaruh Lingkungan Kerja $\left(X_{2}\right)$ Terhadap Kinerja Pegawai (Y)

Menurut uji statistik, didapatkan koefisien determinasi senilai 0,641 atau sebesar 64,1\% sementara sisanya 35,9\% dipengaruhi oleh faktor lainnya. Uji hipotesis didapatkan $\mathrm{t}$ hitung lebih besar dari t tabel atau (10,513 > 1,999), artinya $\mathrm{H}_{0}$ ditolak kemudian $\mathrm{H}_{2}$ diterima berarti ada pengaruh yang signifikan secara sebagian antara lingkungan kerja terhadap kinerja pegawai.

3. Pengaruh Kepemimpinan $\left(X_{1}\right)$ \& Lingkungan Kerja $\left(X_{2}\right)$ Secara Bersamaan Terhadap Kinerja Pegawai (Y).

Menurut hasil penelitian, dinyatakan bahwa kepemimpinan $\left(\mathrm{X}_{1}\right)$ dan lingkungan kerja $\left(\mathrm{X}_{2}\right)$ mempunyai pengaruh terhadap kinerja pegawai dengan didapatkan persamaan regresi $\mathrm{Y}=7,374+0,230 \mathrm{X}_{1}+0,628 \mathrm{X}_{2}$. Ini membuktikan koefisien masing-masing variabel bertanda plus atau positif, berarti bahwa semakin tinggi kepemimpinan dan lingkungan kerja, semakin tinggi pula kinerja pegawainya, sebaliknya jika semakin rendah kepemimpinan dan lingkungan kerja, jadi akan semakin rendah pula kinerja pegawai. Nilai determinasi kepemimpinan dan lingkungan kerja secara bersamaan senilai $68,3 \%$ sedangkan senilai $31,7 \%$ lainnya dipengaruhi oleh faktor lain. Uji hipotesis didapatkan $F_{\text {hitung }}>$ dari $F_{\text {tabel }}$ atau $(65,719>2,760)$, dengan demikian $\mathrm{H}_{0}$ ditolak dan $\mathrm{H}_{3}$ diterima. Ini berarti bahwa ada pengaruh yang signifikan secara bersamaan antara kepemimpinan dan lingkungan kerja terhadap kinerja pegawai. 
KREATIF : Jurnal Ilmiah Prodi Manajemen Universitas Pamulang, Vol. 8, No.2, Desember 2020

\section{KESIMPULAN DAN SARAN}

\section{A. Kesimpulan}

1) Pengaruh yang signifikan antara kepemimpinan dengan kinerja pegawai sebesar $38,5 \%$. Dari uji hipotesis diperoleh $t$ hitung lebih besar dari t tabel atau $(6,226>$ 1,999).

2) Pengaruh yang signifikan antara lingkungan kerja dengan kinerja pegawai sebesar $64,1 \%$. Dari uji hipotesis didapatkan t hitung lebih besar dari t tabel atau $(10,513>1.999)$.

3) Kepemimpinan dan lingkungan kerja mempunyai pengaruh signifikan terhadap kinerja pegawai dengan persamaan regresi $\mathrm{Y}=7,374+0,230 \mathrm{X}_{1}+0,628 \mathrm{X}_{2}$. Makin tinggi kepemimpinan dan lingkungan kerja maka kinerja pegawai juga akan semakin meningkat. Besarnya pengaruh sebesar 68,3\% sementara sisanya sebanyak 31,7\% dipengaruhi faktor lain. Uji hipotesis didapatkan nilai $F_{\text {hitung }}$ lebih besar dari $F_{\text {tabel }}$ atau $(65,719>2,760)$, oleh karena itu $\mathrm{H}_{0}$ ditolak lalu $\mathrm{H}_{3}$ diterima. Ini berarti bahwa ada pengaruh yang signifikan secara bersama-sama antara kepemimpinan dan lingkungan kerja terhadap kinerja pegawai PT. Victory Chingluh Indonesia Divisi Quality.

\section{B. Saran}

1) Pimpinan PT. Victory Chingluh Indonesia Divisi Quality hendaknya mampu berperilaku yang baik sehingga dapat dijadikan contoh oleh karyawan.

2) Agar lebih maksimal lagi perusahaan seharusnya memperbaiki fasilitas penerangan sesuai kebutuhan agar mampu melancarkan aktifitas pekerjaan karyawan.

3) PT. Victory Chingluh Indonesia Divisi Quality hendaknya memberikan reward kepada karyawan yang memiliki kemampuan menciptakan produk yang berkualitas.

\section{DAFTAR PUSTAKA}

Abdullah, M. Maruf. (2014). Manajemen dan Evaluasi Kinerja Karyawan. Jakarta : Penerbit Aswara Pressindo, pp. 3-4.

Arianto, Nurmin (2018). Pengaruh Kepemimpinan Terhadap Kinerja dan Kepuasan Kerja Karyawan. JENIUS : Jurnal Ilmiah, Manajemen Sumber Daya Manusia Universitas Pamulang, 1(3),260-280.

Arianto, Nurmin (2020). Kepemimpinan dan Komunikasi Pengaruhnya Terhadap Kinerja dengan Kepuasan Kerja Sebagai Variabel Intervening. Kreatif: Jurnal Ilmiah Prodi Manajemen Universitas Pamulang, 8 (1), 124-137.

Arianto, Nurmin (2020). Pengaruh Motivasi dan Lingkungan Kerja Terhadap Kinerja Karyawan. JENIUS : Jurnal Ilmiah, Manajemen Sumber Daya Manusia Universitas Pamulang, 3(3), 312-321

Danang, Sunyoto. (2015). Analisis Data Ekonomi Dengan Menggunakan SPSS Cetakan I. Jakarta: Penerbit PT. Indeks, pp.42-43 
KREATIF : Jurnal Ilmiah Prodi Manajemen Universitas Pamulang, Vol. 8, No.2, Desember 2020

Ghozali, Imam (2012). Aplikasi Analisis Multivariate dengan Program IBM SPSS 19 (Edisi Kelima). Semarang : Penerbit Universitas Diponegoro. Pp.142.

Santoso, Singgih (2009). SPSS Statistis Parametik Cetakan kedua. Jakarta : Penerbit PT. Elek Media, pp. 342.

Siagian, Sondang, P. (2014) Manajemen Sumber Daya Manusia. Jakarta : Penerbit PT. Bumi Aksara, pp. 56.

Sugiyono, (2012). Metode Penelitian Bisnis. Bandung : Penerbit Alfabeta, pp. 115-116.

Sunarto, Ading (2019). Analisis Kinerja Karyawan Pada PT. Bank Mandiri Cluster Cilegon 1. Scientific Journal Of Reflection : Economic, Accounting, Management and Business, 2(3), 241-250

Sunarto, Ading (2020). Kinerja Karyawan Berbasis Kepemimpinan Dan Motivasi Pada PT. Duta Jaya Putra Persada Mining. JENIUS : Jurnal Ilmiah, Manajemen Sumber Daya Manusia Universitas Pamulang, 3(3), 246-257

Sunarto, Ading (2020). Pengaruh Gaya Kepemimpinan, Motivasi, Serta Disiplin Kerja Terhadap Kinerja Karyawan (Study di PT. Mitsui Leasing Capital Indonesia Abdul Musi - Jakarta Pusat). KREATIF : Jurnal Ilmiah Prodi Manajemen Universitas Pamulang, 8(1), 18-38

Supangat, Andi (2008). Statistika Dalam Kajian Deskriptif, Inferensi, Dan Non Parametik. Jakarta : Penerbit Kencana Prenada Media Group, pp. 2-3

Suryono, Ekatama, (2015). Cara Gampang Mengubah Karyawan Menjadi Aset Produktif \& Menguntungkan. Jakarta : Penerbit Elek Media Komputindo, pp. 224.

Sutikno, (2014). Pemimpin dan Kepemimpinan. Lombok : Penerbit PT. Holistica, pp.1516.

Wirawan, (2015). Manajemen Sumber Daya Manusia Indonesia. Jakarta : Penerbit Raja Grafindo Persada, pp. 735. 